\section{Richard Charles Harrington}

Formerly Professor in Child and Adolescent Psychiatry, University of Manchester

This additional commemorative piece was kindly submitted following the obituary published in Psychiatric Bulletin, November 2004, 28, 429.

Richard (also known as 'Dick') was born in Birmingham, the son of a psychiatrist. He was educated at Bedford School, then graduated from Birmingham University Medical School in 1980, gaining a distinction in psychiatry. He trained in psychiatry at the Maudsley Hospital, and in 1984 gained his MPhil at the Institute of Psychiatry. In 1991 he achieved his MD from the University of Birmingham where he worked as senior lecturer in child and adolescent psychiatry.

A Fellow of the Royal College of Psychiatrists, through his early distinguished research career he changed the face of both theory and clinical practice in the field of depression in childhood and adolescence. In an important follow-up study of children at the Maudsley Hospital, he demonstrated that depressive conditions in the school-age years, could both persist and recur with an associated risk of recurrent depressive illness, a poorer work record and greater instability in intimate relationships in adult life. Those who became depressed as adolescents fared worse in the long term than those who experienced depression pre-puberty. With the emerging knowledge of the early 1990s on genetic predisposition to depressive disorder, Richard found that although depression starting in adolescence is likely to be partly genetic in origin, depressions in childhood are due almost exclusively to adverse environments.

In 1993 Richard took up his Chair in Child and Adolescent psychiatry at the University of Manchester. From there on, for those of us in the north west, whether clinicians from across the multidisciplinary team or researchers, we grew to know, value, and cherish his work, and his uniquely engaging personality.

A clinician's professor, Richard always applied his research skills, his indefatigable energy and enthusiasm, to the betterment of children's mental health services with the introduction of innovative, evidencebased treatments for children suffering with a range of psychiatric disorders.
As a research active clinician I was greatly privileged to work with Richard. He led a stream of research into the origins of antisocial, aggressive and hyperactive behaviour, utilising knowledge gained in his childhood depression studies on new treatments for children and adolescents with behavioural disorders and protocols for model treatments including group treatments for adolescents who had repeatedly harmed themselves.

You always knew when Richard was in the building with that sound of laughter accompanying earnest discussion about a new project. Whether research or practice, he was never afraid to alert and inform the public through media discussions. His policy and advisory work such as the National Institute for Clinical Excellence guidelines on what treatments could and should be provided for children greatly shaped evidence-based practice.

His pioneering research was acknowledged internationally by the American Academy of Child and Adolescent Psychiatry, who, in 1998, bestowed upon him, the prestigious Nathan Cummings Foundation Award for best original research on depression in young people.

Over the next 10 years Richard established one of the most active and productive child and adolescent psychiatry research groups in the world. At the same time he was an active clinician, for a period of time taking the role of senior clinical leadership in the Department of Child Psychiatry at the Royal Manchester Children's Hospital where he was respected and valued by paediatric colleagues and by those shaping policy and practice across the region. Developing detailed protocols for 'model' treatments evaluated in clinical trials, Richard developed a national and international reputation. His 'regional study days' were a packed house.

He gave generously and genuinely of his time to develop and nurture research across all mental health disciplines, pioneering and supporting in particular the research careers of nurses and, in my own case, 'late onset' professors. He had gathered together a group of young researchers and research active specialist registrars and nurses who will always be part of the 'Harrington School'.

He took his research talents, sense of humour, enthusiasm and dedication out into his international work as Chairman of the British Child Psychiatric Research Society and in his role as Vice President of the European Society of Child and
Adolescent Psychiatry. Richard served on the Scientific Committee at the Wellcome Trust and the Department of Health. He published numerous peer-reviewed papers and articles, together with three books.

At the time of his death he was actively engaged in a multi-site randomised controlled trial of antidepressants with and without cognitive-behavioural therapy in children and a series of ongoing studies into antisocial behaviour to develop the skills and knowledge of practitioners in the youth justice system.

As one of the most promising and original researchers and clinicians internationally, he had many tasks and positions waiting for him.

Richard met his wife Lesley at the Institute of Psychiatry and they were both involved in research projects for Sir Michael Rutter. Richard was a loving husband and father; part of an exceptional family.

In all too short a life, Richard made a real lifetime's contribution to the betterment of the lives of thousands of children and has shaped and influenced child psychiatric practice and research for years. His family of colleagues will greatly miss his energy, intelligence, humour, friendship and warm-hearted personality, but will never lose the influence of his wisdom, or memories of him.

Sue Bailey

\section{Linford Llewelyn Rees}

\author{
Henry R. Rollin has submitted this \\ personal insight into the rich life of \\ Linford Llewelyn Rees, whose obituary \\ appeared in Psychiatric Bulletin, \\ November 2004, 28, 428.
}

It may seem surprising, even contradictory, to learn that Linford, cerebral as he most certainly was, as a young man was passionately devoted to ballroom dancing: to such a degree, indeed, that he, partnered by his then fiancée, Katherine, were renowned competitors, and, not infrequently, winners of ballroom dancing competitions held in Wales. Cash prizes were particularly welcome to augment the then slender financial resources.

Henry R. Rollin 